\title{
De Indígena a Imigrante: O Lugar da África e dos Africanos no Universo Imaginário Português dos Séculos XIX ao XXI ${ }^{1}$
}

\author{
Anderson Ribeiro Oliva*
}

Resumo: O presente artigo tem como objetivo maior percorrer as trajetórias seguidas pelas representações fabricadas sobre os africanos no imaginário contemporâneo português, destacando os cenários mentais construídos do período que antecede a montagem do processo colonial lusitano na África até os dias atuais, com as ondas imigratórias de africanos em direção ao continente europeu.

Palavras-chave: Representações; África; imaginário português.

Abstract: This article is intended to go through the paths followed by representations made about Africa in contemporary portuguese imaginary, emphasizing the mental scenarios constructed in the period preceding the assembly of the lusitanian colonial process in Africa until the present day, with the waves of immigration from Africa towards the European continent.

Keywords: Representations; Africa; portuguese imaginary.

\section{Os cenários mentais lusos}

No esforço de decifrar o lugar ocupado pelos africanos no universo mental dos portugueses, no período correspondente aos dois últimos séculos, podemos encontrar um conjunto multifacetado e complexo de representações e construções imaginárias. Mesmo que essas imagens fabricadas não sejam homogêneas e nem exclusivas - já que possuem vários pontos de interseção e complementação - elas revelam como as relações históricas contemporâneas tecidas entre Portugal e a África influenciaram os mecanismos utilizados no esforço de entender, diferenciar, tentar incorporar ou rejeitar o Outro, empregados por um dos lados dessas moedas identitárias.

Dessa forma, a intenção principal deste artigo é identificar alguns dos ingredientes que participaram da construção das idéias e das imagens circulantes na sociedade portuguesa durante o citado recorte temporal, sobre a África e os africanos. Neste caso, iremos destacar tanto os imaginários construídos ao longo do período colonial - que não são homogêneos - como aqueles em fomentação nas últimas três décadas, já no período pós-colonial. Compete lembrar ainda que o maior conjunto de representações elaboradas sobre os africanos encontra sua origem no intervalo que se estende da segunda metade do século XIX até a década de 1970, e que corresponde às intenções inicias, à montagem e à

\footnotetext{
${ }^{1}$ Este trabalho recebeu apoio financeiro da Coordenação de Aperfeiçoamento de Pessoal de Nível Superior (Capes).

* Doutor em História Social pela Universidade de Brasília (UnB) e professor de História da Universidade Federal de Goiás (UFG) - oliva@unb.br
} 
desarticulação da presença colonial lusitana em África ${ }^{2}$. A essas referências mentais juntouse um novo conjunto de representações que passou a ser construído a partir da queda do regime salazarista e estendeu-se até a primeira década do século XXI. Neste momento, marcado pelas novas relações migratórias que levaram para Portugal milhares de africanos e pela formação das primeiras gerações de afro-portugueses, ou seja, de filhos de africanos nascidos em Portugal, percebeu-se um intensificar de velhos e novos estereótipos. Vejamos, portanto, quais foram as mais recorrentes imagens geradas sobre os africanos em alguns desses momentos citados.

\section{As construções imagéticas colonialistas: primitivos, indígenas e colonizados}

Para a historiadora Isabel Castro Henriques, se quiséssemos lançar um olhar panorâmico acerca do período colonial português, poderíamos apontar para pelo menos seis grandes conjuntos de idéias que alimentaram o discurso lusitano sobre os africanos, e consequentemente constituíram parcialmente o imaginário em terras européias acerca da África. Articulados ao longo dos séculos XIX e XX, atuando com maior intensidade em certos momentos e silenciados em outros, esses elementos permitem que visualizemos, ao mesmo tempo, a essência da lógica colonial no calor de sua vivência temporal e alguns dos ecos que nos chegam do passado, com freqüências e volumes diversos, mas ainda bastante esclarecedores sobre as maneiras do português ver o Outro/africano. Filhos da ficção ou de algumas dimensões da realidade, ingredientes de gênese manipulada ou do uso vulgarizado por parte da população portuguesa de estereótipos e clichês, o que interessa notar é que essas substâncias da ideologia colonial foram divulgadas por décadas no imaginário coletivo lusitano, tanto por meio dos manuais escolares, como pelos recursos de comunicação social, e, de certa forma, formataram as imagens que grande parte dos portugueses carregavam sobre os africanos (Henriques, 2004, pp. 35-44).

Sintetizando o argumento da historiadora, esses instrumentos teórico-ideológicos foram os seguintes: o "papel pioneiro de Portugal no processo de expansão européia"; "a idéia da superioridade do branco/civilizado contrastando com inferioridade do negro/primitivo"; a "idéia da missão civilizadora dos portugueses"; "a presença multissecular de Portugal em África"; a "natureza tropicalista do povo português"; e, por fim, a "ausência de racismo dos portugueses" (Henriques, 2004, pp. 51 e 304).

\footnotetext{
2 Sentimos-nos forçados a enfatizar que dentro do recorte eleito para observação encontramos vários conjuntos de imagens e de representações formulados sobre os africanos e a África. Muitos desses se articularam, influenciaram ou se sucederam em um jogo multidirecional de contribuições. Outros se revelam cristalizados. Alguns não existem mais.
} 
Já para o também historiador, Valentim Alexandre, é inquestionável o lugar ocupado pelo continente africano na construção do imaginário político em Portugal dos últimos dois séculos, assim como das imagens depreciativas geradas sobre os africanos. De forma semelhante a Henriques, apesar das conclusões um tanto diferenciadas, ele aponta para uma série de estratégias ideológicas empregadas por políticos, intelectuais e cientistas no esforço de legitimar a presença colonial portuguesa em África. Segundo Alexandre, existiram duas teses ou mitos centrais que condicionaram as ações e leituras portuguesas acerca dos universos africanos durante o período colonial: “o mito do Eldorado" e o "mito da herança sagrada". Como desdobramento ou elementos constituintes desses, podemos encontrar uma série de outras idéias e teorias, digamos, auxiliares que serão à frente abordadas (1995, pp. 231-233). Quais seriam, portanto, no citado período, os pigmentos e contornos que receberiam os africanos sob o olhar português? Apesar de não conceder um espaço a todas as expressões imagéticas constituintes desse olhar, os elementos a seguir auxiliam-nos na compreensão de parte desses jogos de imagens.

Em um primeiro momento que vigorou até a década de 1870, podemos constatar a presença de uma lógica influenciada principalmente pela ideologia escravagista do Antigo Regime. Neste caso, parece-nos certo que as representações e imagens mais destacadas acerca dos africanos eram as dos indivíduos sem autonomia, ou do seres coisificados pela ação dos mercadores de escravos, pelo trabalho forçado e pelos castigos corporais. Motivada pela perda do Brasil na década de 1820, pelas influências do pensamento liberal e pelos postulados do iluminismo, nos anos que se seguiram à saída dos portugueses da América, ocorreu uma leve mudança da imagem do africano para o português. De sujeito sem status jurídico e imerso nas justificativas teológicas e morais da escravidão, as representações sobre os homens e mulheres do continente passariam, no momento de maior importância para a construção do "império português" em África, ou seja, as últimas décadas do século XIX e as primeiras do XX, a ser produzidas a partir das novas ondas ideológicas que varriam os pensamentos lusitanos.

Entre 1870 e 1890, como expressão das influências da corrente de humanitarismo liberal, conduzida por Sá da Bandeira - contrária à escravidão ${ }^{3}$ e defensora do fim do trabalho servil nas colônias ${ }^{4}$ - os africanos passaram a ser vistos como "seres decerto atrasados, devido a circunstâncias históricas acidentais, mas capazes de progredir e de se integrarem como cidadãos no corpo nacional' (Alexandre, 1995, pp. 234). Porém, a brisa humanista não suportou o

\footnotetext{
3 O fim do tráfico de escravos para Portugal data de 1761, à época do Marquês de Pombal. Já o fim da escravidão em todo o império português é de 25 de Fevereiro de 1869.

${ }^{4}$ De fato abolido em 1875, apesar da persistência de formas de trabalho compulsório e dos castigos corporais nas décadas seguintes.
} 
esfacelamento do projeto da construção de um império territorial português que ligasse o Atlântico ao Índico na África Central, barrado pelo poderio e influência britânica na região. $\mathrm{Na}$ realidade, a celeuma acerca do "Mapa Cor-de-rosa", projeto expansionista na África austral, obstruído pela Conferência de Berlim ${ }^{5}$, tornou-se um dos motores ou ingredientes da ideologia colonial portuguesa nas décadas seguintes, sendo reiteradamente abordada como uma afronta aos "Direitos históricos" portugueses na área. A fragilidade da tese de que a região pertencia a Portugal, por ter sido por ele descoberta, foi instrumento ativo no imaginário português e nas lições de história ministradas nas escolas. Mais do que isso, a equivocada perspectiva de que em Berlim definiu-se a divisão da África pelas potências imperialistas foi reproduzida e intensificada ao longo dos anos (Ver Borges, 1995, pp. 1-2; e Hernandez, 2005, p. 142).

A partir de 1890, o chamado projeto colonial vai constituir-se em um dos elementos centrais da sedimentação e formatação do nacionalismo luso. Até a década de 1920, talvez pelas maiores influências do pensamento antropológico, embebido pelo Darwinismo Social, ou pelo impacto causado pelas lutas de resistência protagonizadas pelos africanos nos "sertões" do continente, prevaleceu uma imagem bastante dura sobre suas populações: os "indígenas" não deveriam ser assimilados, mas sim, dirigidos pelos colonos e excluídos do ethos lusitano. Sendo uma de suas figuras mais emblemáticas do início desse período, o pensador João Pedro de Oliveira Martins (1845-1894), que sintetizou em algumas passagens de suas obras a relação imaginária construída naqueles anos sobre os africanos, como a retratada a seguir.

\begin{abstract}
Sempre o preto produziu em todos esta impressão: é uma criança adulta. A precocidade, a mobilidade, a agudeza própria das crianças não lhe faltam; mas essas qualidades infantis não se transformam em faculdades intelectuais superiores. Resta educá-los, dizem, desenvolver e germinar as sementes. (...) Não haverá, porém, motivos para supor que esse facto do limite da capacidade intelectual das raças negras, provado em tantos e tão diversos momentos e lugares, tenha uma causa íntima e constitucional? Há decerto, e abundam os documentos que nos mostram no negro um tipo antropologicamente inferior, não raro próximo do antropóide, e bem indigno do nome de homem (MARTINS, 1978, pp. 262).
\end{abstract}

Ao longo desse período - se estendendo para anos anteriores e posteriores ao recorte estabelecido - outro fenômeno deve ser destacado no entendimento da elaboração

\footnotetext{
${ }^{5}$ Sabemos que a Conferência de Berlim foi recoberta por uma série de tendenciosas interpretações pela historiografia tradicional. Porém, estamos considerando acima de tudo os debates imperialistas e a disputa entre Portugal e Inglaterra acerca da África Austral. Sobre os debates acerca da Conferência de Berlim ver, Uzoigwe (1991), Borges (1995) e Döpcke (1999, pp. 81-85).
} 
das representações sobre as populações em África: a transição da imagem associando o africano à escravidão para aquela que o relacionava à condição de "indígena" .

Estava encontrada a via astuciosa e eficaz que permitia a exploração dos africanos: os absolutamente não civilizados são transformados em indígenas. Se literalmente o termo designa "os nascidos no país", adquire agora uma funcionalidade pejorativa que desqualifica e serve para designar aquele que por essa razão está condenado ao trabalho obrigatório (HENRIQUES, 2004, p. 294).

De acordo com Isabel Castro Henriques tal transformação imaginária deveria responder tanto à necessidade de obtenção de mão-de-obra barata e minimamente qualificada, para ser integrada às redes de produção européias, como para demarcar as fronteiras entre o civilizado e o selvagem e seus papéis no "novo mundo" criado na região.

É neste contexto que se afirma a criação do indígena. Torna-se então indispensável uma operação de re-elaboração da representação do africano: uma nova imagem onde os marcadores da inferiorização do negro sejam imediatamente visíveis e identificáveis para o mais analfabeto dos cidadãos portugueses. A função dessa revisão da imagem é evidentemente dupla: por um lado, trata-se de por em evidência o carácter congênito da selvajeria o que explica o recurso constante às explicações biológicas; por outro, a própria selvajeria da imagem serve para justificar a imposição de uma ferocíssima disciplina do trabalho (Idem, pp. 287-8).

O historiador Valdemir Zamparoni, em um detalhado estudo acerca das estratégias e instrumentos empregados para a exploração do trabalho "indígena" na África Oriental de ocupação lusitana, também sinaliza para o lugar ocupado pelas sociedades africanas no imaginário português, ou pelo menos, dos ingredientes necessários para transformá-los em seres civilizados.

Já que consideravam impossível elevar os indígenas, tidos como selvagens e indolentes, à condição de cidadãos pela via da educação, o único caminho para a civilização passaria necessariamente pelo trabalho na esfera capitalista. Imbuídos da fé pretensamente natural e universal de que o trabalho e a acumulação de seus frutos era a base de toda a vida, individual e social, faziam crer que aos civilizadores era imposta a tarefa de arrancar o indígena deste estado natural de indolência e ociosidade e submetê- lo a uma disciplina do trabalho, alterando sua conduta diante do mesmo (...) (ZAMPARONI, 1998, pp. 34-35).

A ênfase nas diferenças civilizacionais entre europeus e africanos se tornou o alicerce fundamental, tanto para o convencimento interno - ou seja, na formação de uma opinião pública favorável aos esforços de ocupação e exploração dos territórios coloniais -

\footnotetext{
${ }^{6}$ Sobre a temática consultar os textos de Isabel Castro Henriques (Henriques, 2004, pp. 285-297), e de Valdemir Zamparoni (Zamparoni, 1998, pp. 13-42 e 2007).
} 
como externo - para os próprios colonizados e demais potências européias participantes do processo - de que a presença portuguesa em África seria algo desejável e irrevogável. O "fardo do homem negro" ou do africano seria espelhado pelo seu esforço em se tornar útil ao "paternal" olhar ocidental, sendo o mais rápido possível civilizado pelos europeus. No estado "selvagem" não estaria apto ao trabalho" ou para seguir as leis ocidentais. Em algumas partes da Europa, a figura de homens e mulheres negros que se submetiam aos serviços e vontades impostas pelos europeus, se confundia com a imagem ambígua de grupos "primitivos" que ainda habitariam os interiores ou regiões isoladas do continente africano (HENRIQUES, 2004, p. 92).

Outra forma de revelar os "benefícios" da ocupação européia era evidenciar os avanços tecnológicos implantados, quase todos, no exclusivo sentido de baratear os custos com a exploração colonial e permitir a acomodação de mais colonos brancos. A historiadora Isabel Castro Henriques lembra que as ferrovias, os barcos a vapor e as cidades seriam símbolos dessas ações e da lembrança de que os africanos em seu estado de "enselvajamento" teriam condições apenas de construir pequenos barcos em troncos de árvores e aldeias de palha. Assim, novamente, a presença lusa serviria como um presente do mundo civilizado ao progresso dos africanos (HENRIQUES, 2004, pp. 415-431).

Temos, portanto, entre os anos de 1870 e $1920^{\circ}$, a presença vitoriosa no imaginário português, mesmo que não exclusiva, das representações e argumentos que reforçavam a crença de que os africanos ou os "indígenas" seriam comprovadamente "selvagens e atrasados". Contaminada pelas lutas de resistência, na ótica lusa, chamadas de "pacificação", ocorridas tanto em Angola como em Moçambique, finalizadas apenas na segunda década do século XX, e pelo calor das teorias raciais, a imagem do africano era simbolizada pela rejeição, aversão ou estranhamento?. Alguns dos ideólogos do colonialismo lusitano chegavam a defender a eliminação, por ação do homem ou do tempo, das populações "indígenas", porém a tese de maior expressão e vigor era a de submetê-las para melhor explorá-las, sem qualquer contrapartida, a não ser a apresentação de uma das faces mais frias e duras do chamado mundo civilizado europeu (ALEXANDRE, 1995, pp. 234-5).

\footnotetext{
7 Para uma apurada observação da questão do trabalho na perspectiva colonial portuguesa ver Zamparoni (1998 e 2007).

8 Veremos a seguir com maior detalhamento o debate montado em Portugal acerca da "condição do africano". Apenas como instrumento de maior esclarecimento de nosso ponto de vista, alertamos que não desconhecemos a existência no período das teorias oriundas de um pensamento humanista, que defendia a possibilidade de assimilação ou ascensão cultural dos povos ditos primitivos.

${ }^{9}$ Como a invenção da monstruosidade de Gungunhana, líder africano na guerra de resistência dos vátua perante os portugueses na última década do século XIX. Ver Henriques (2004, pp. 95-96).
} 
A partir de 1930, percebe-se um outro movimento ideológico em relação ao elemento humano das colônias portuguesas. Depois da implantação do Estado Novo de Salazar e da elaboração textual de sua expressão jurídica, econômica e política para as colônias, o Acto Colonial de 1930, a tentativa do governo português foi a de potencializar e centralizar a exploração econômica e os projetos de gestão e investimento nos territórios coloniais. Soma-se a essa perspectiva o aumento das ações voltadas para divulgar a importância do Império Colonial português, seja por meio da propaganda oficial seja por meio do sistema de ensino (LÉONARD, 1999, pp. 19-22).

Ao analisar a legislação colonial do período relativo ao final do século XIX e das primeiras décadas do XX, Valdemir Zamparoni, identifica ritmos distintos empregados pela ótica colonialista para se pensar, classificar e lidar com as sociedades africanas. Existe uma óbvia transição de um modelo liberal, que percebia "na parcela mestiça da população colonial" possíveis aliados para controlar e explorar os "indígenas", para um modelo que sinaliza para a efetiva implantação do sistema colonial português, voltada para atender os interesses de colonos e administradores portugueses.

\begin{abstract}
(...) a legislação liberal das últimas décadas do século XIX foi editada ainda antes que se houvesse efetivado o domínio militar sobre os potentados africanos e antes de instalada a máquina administrativa colonial; isto sugere que a metrópole esperava contar com a parcela mestiça da população colonial para assegurar não só frutuosos negócios, mas também seus próprios interesses estratégicos (...). Esta legislação liberal foi elaborada nos salões lisboetas e os ideais que as embasavam eram de certa forma mais difusos e abstratos; já a legislação posterior, inicialmente gestada e editada nas colônias e depois incorporada pela Ditadura, reflete os interesses imediatos dos colonos e dos administradores diante das realidades africanas, bem como o já avançado processo de exclusão e segregação rácicosocial a que foram submetidos os indígenas e "filhos da terra", nas colônias, a partir da ocupação efetiva do território conquistado manu militari. A prática, entretanto, era muito mais excludente que a lei (...) (ZAMPARONI, 1998, p. 490).
\end{abstract}

De acordo com Valetim Alexandre (1995, pp.237-8), apesar das divergências apresentadas pelas posições teóricas de dois dos principais expoentes da Política Colonial portuguesa do período - Norton de Matos e Armindo Monteiro -, até 1950, as posturas ideológicas acerca dos territórios e populações africanas estariam marcadas pelo nacionalismo exacerbado e pelos olhares paternalistas e depreciativos lançados de Portugal. Para ambos os ideólogos citados, o africano era pensado como "um elemento das raças primitivas, na maioria ainda em estado selvagem, entregues à miséria, à superstição e a ignorância”. Seria uma missão para os portugueses, "por imperativo histórico, a tarefa de os 'elevar' e de os chamar à civilização". A grande divergência entre eles se encontrava no campo das explicações para a correção dessa inferioridade inata ao africano. Para Norton de Matos 
seria uma questão passível de ser resolvida ao longo do tempo, por meio de uma fusão entre o elemento africano e o elemento português. Já para Armindo Monteiro ela espelharia a relação de imperfeição racial do africano, que o condenaria ao eterno atraso.

De 1930 a 1950, como recurso para garantir o sustento econômico da Metrópole e para acatar as teses sobre a incapacidade e preguiça inatas ao elemento "indígena" presente nas Colônias, prevalece a lógica e as práticas explicitadas pelo Estatuto do Indígena, pautadas na exploração do trabalho e na formulação de uma política educacional excludente e de sentido pragmático (civilizar o "indígena” e treiná-lo para o trabalho nas escolas do chamado "Ensino Rudimentar"). Percebe-se também os inúmeros obstáculos apresentados aos africanos para que estes pudessem ser considerados civilizados, ou na melhor expressão do período, transformarem-se em portugueses (PAULO, 2000, pp. 304-306 e 310-315). Em Portugal o período foi marcado também pela organização dos Congressos e Exposições Coloniais que, contando com a visita de milhares de pessoas nas duas principais cidades do país (Lisboa e Porto), auxiliaram na divulgação da propaganda colonialista para o cidadão comum, com ênfase para as dificuldades enfrentadas no além-mar e a imperiosa tarefa que se apresentava a Portugal de civilizar os "indígenas"10.

Elemento exótico, explicado apenas pelas teses racistas e fadado à ação paternalista européia, a imagem do africano no imaginário português fundiu-se, ao longo dessa trajetória, cada vez mais com a perspectiva que associava os africanos aos trabalhos servilcompulsórios, e ainda mais com a idéia do ser primitivo, ignorante, inferior, infantil, incapaz e de hábitos perigosos (VALVERDE, 1997, pp. 76-89).

Talvez, uma das imagens mais desconcertantes utilizadas neste período tenha sido a defendida pelo antropólogo/militar português Henrique Galvão que, em livro publicado em 1947, intitulado Antropófagos, reforçava os estigmas multisseculares acerca da existência de práticas antropofágicas entre os africanos, com argumentos acobertados pela equivocada perspectiva científica de seu trabalho ${ }^{11}$.

A questão do canibalismo e das suspeitas da sua prática não foi aproximada apenas na base do riso ou do pânico que pode gerar. Ela foi colocada, por alguns autores, no centro da justificação histórica do colonialismo português. (...) em 1947, Henrique Galvão publicou o livro Antropófagos, baseado em testemunhos de práticas canibais, supostamente verdadeiras, ocorridas no Norte de Angola nas décadas de 30 e 40. Deste modo, era reconfirmada a legitimidade da continuada presença portuguesa com vista à erradicação, em pleno século $\mathrm{XX}$, de "práticas contrárias aos ditames da humanidade” (VALVERDE, 1997, pp. 89-90).

\footnotetext{
${ }^{10}$ Entre algumas dezenas de eventos e publicações podemos citar a I Exposição Colonial, ocorrida no Porto, em 1934, e a Exposição do Mundo Português, de 1940, em Lisboa ver Leonard (1999, pp. 24-28).

11 Ver também a excelente exposição acerca da questão feita por Isabel Castro Henriques, (2004, pp. 241244).
} 


\section{No "mundo" que o português criou o espaço reservado aos africanos}

A partir de 1950, com a nova ordem mundial pós Segunda Guerra, têm início os processos de independência em África. Desde então as pressões de ordem internacional e as inquietações tanto em Portugal como nas próprias colônias, contribuíram para a fabricação de uma leitura marcada pela perspectiva da “formação de um 'Portugal maior', da 'nação una' espalhada pelos vários continentes, cadinho onde se fundiriam os diversos povos e as diferentes raças" (ALEXANDRE, 1995, p. 237). Tal postura seria, de certa forma, herdeira daquela inaugurada durante os anos que se seguiram ao Ultimatum britânico, e se encontrava fundamentada em duas perspectivas, reforçadas e potencializadas pelo Estado Novo: os descobrimentos lusos e a formação do chamado "império ultramarino", entre os séculos XV e XVI, deveriam projetar uma imagem positiva e grandiosa de Portugal, assim como a presença portuguesa em África durante séculos legitimaria sua posição colonial na área (LÉONARD, 1999, pp. 22-25; ALEXANDRE, 2000, pp. 22-26).

De acordo com os historiadores que se debruçaram sobre o tema, no momento seguinte, transcorrido entre 1950 e 1970, as imagens compostas sobre os africanos e o papel da África perante o cenário mental português transitaram entre dois conjuntos de representações.

O primeiro, que poderíamos descrever como sendo uma mutação das referências do período anterior, projetava o africano ainda como ser primitivo, mas que de alguma forma passava à condição de membro, distante e ainda rejeitado, do "mundo português". Ela resultava da idéia defendida pelos ideólogos de que os conjuntos populacionalterritoriais africanos deveriam ter sua importância, enquanto integrantes do império português, reconhecida e incorporada pelos portugueses (LÉONARD, 1999 a, pp. 31-45).

Evidente que essa seria uma parte subsidiária e, em vários aspectos, inferior do mundo português, e, era mais claro ainda, que tanto a existência de características culturais positivas, como as referências históricas africanas relevantes continuavam a não ser lembradas nos discursos colonialistas. Assim, ainda mais que nas décadas anteriores, os "nativos"/“indígenas" que possuíssem alguma intenção de superar seus "atrasos" deveriam aceitar a presença portuguesa e copiar seus modos de viver. O modelo de vestir, a arquitetura das cidades, a estrutura de educação formalizada, a religião cristã, a língua portuguesa e a ideologia do trabalho deveriam ser adotados por todos aqueles que quisessem ascender ou ter algum tipo de direito na sociedade colonial. De fato, os 
obstáculos interpostos para ascensão dos "indígenas" à condição de cidadão português, responsáveis pela irrisória mobilidade dentro da sociedade colonial, apenas sinalizam as reais intenções e leituras realizadas sobre o continente a partir da ótica colonial (ZAMPARONI, 2007, pp. 45-112 e HENRIQUES, 2004, pp. 299-320).

A segunda imagem, que se fortalece a partir dos anos 1950, não retira o status da inferioridade das sociedades intituladas de "indígenas", mas defende com maior ênfase a possibilidade de assimilar seus indivíduos ao universo "civilizatório" europeu, transformando-os em cidadãos portugueses de segunda ou terceira ordens, mesmo que na prática poucos tenham "conquistado" essa condição. Com o crescimento dos movimentos de independência africanos, uma nova tese foi incorporada ao também novo discurso lusitano para sua situação colonial. Portugal precisava justificar perante a opinião pública interna, perante a $\mathrm{ONU}^{12}$ e perante o mundo a sua insistente permanência no continente na condição de "império ultramarino", quando existia um contra-fluxo evidente e irreversível de expulsão ou retorno dos "impérios europeus" para o velho mundo.

Assim, nessa década e nas seguintes, o Estatuto Colonial foi reformulado e as "possessões" portuguesas migraram do status de Colônias para o de Províncias Ultramarinas. Aos poucos também o Estatuto do Indígena foi sendo flexibilizado e colocado de lado. A idéia, já parcialmente presente nos discursos anteriores, era transformar o "indígena" em civilizado, só que agora em uma perspectiva integrada ao "mundo português". Assim não haveria negros ou brancos no Grande Portugal, mas apenas portugueses. A única, e praticamente inatingível exigência, era a de que os "indígenas" fossem assimilados pela cultura portuguesa e se comportassem como portugueses de fato ${ }^{13}$, o que iria ocorrer poucas vezes (ver Pinto, 1999, pp. 51-64).

Nesse caso, ganhavam destaque as teses do lusotropicalismo, com a perspectiva emblemática de ver no português um indivíduo condicionado e com a capacidade inata de se adaptar e de fundar novos mundos nos trópicos, se confundindo, misturando e assimilando as populações nativas. A apropriação e reinvenção das teorias de Gilberto Freyre serviriam, ao regime salazarista, como instrumento de legitimação científica para sua intransigente postura de não abandonar o "império" africano (HENRIQUES, 2004, pp. 304-5 e ZAMPARONI, 1998, pp. 537). De acordo com Valentim Alexandre defendia-se a suposta capacidade "dos portugueses para se unirem aos trópicos por uma união de amor e não de

\footnotetext{
12 A entrada de Portugal na Organização das Nações Unidas - ONU - ocorreu em 1955.

13 Para ser considerado assimilado - uma das condições exigidas para se tornar cidadão português - o "indígena" deveria usar corretamente a língua portuguesa, ter competência de leitura e escrita, apresentar bom comportamento e atitudes cívicas, possuir rendimentos suficientes e cumprir o serviço militar (ver Paulo, 2000, p. 316).
} 
interesse, baseada sobre a compreensão e a adesão aos valores das culturas que encontravam nas regiōes de ultramar" (ALEXANDRE, 1995, p. 240). Apesar disso, a política portuguesa para a África não conseguiria inverter as imagens geradas sobre os africanos.

As perspectivas de integrar o africano ao universo da "identidade lusa" e transformá-lo em um português "autêntico", mescladas ao argumento da ausência de racismo e da não violência na relação entre os portugueses e os africanos, se transformariam apenas em ingredientes para a formulação de mais alguns mitos que ocupariam parte do imaginário português sobre os africanos. Assim, todos - portugueses e africanos - fariam parte de uma mesma pátria, e, o que os afastava era simplesmente a condição de ser ou não civilizados. Condição essa que passa ao plano secundário com o aparecimento dos movimentos de independência na "África portuguesa" nos anos 1960, acompanhando às lutas de libertação em outras partes de África. As "guerras coloniais" forçaram o governo português a, de fato, maquiar as principais medidas de cerceamento e exclusão dos africanos, mesmo que a ascensão do "indígena” à condição de cidadão português continuasse a ser uma exceção e não a regra.

Provocando uma grave crise de regime, a guerra deu impulso necessário à eliminação das estruturas sociais arcaicas que subsistiam nas colônias de Portugal em África, em maior ou menor grau - desde o trabalho forçado e as culturas obrigatórias ao Estatuto do Indigena -, todas elas abolidas em 1961 (ALEXANDRE, 2000, p. 26).

O início da "guerra colonial", na ótica portuguesa, ou da guerra de independência, ao olhar africano, e sua epígrafe em meados da década de 1970, tiveram um papel decisivo na construção do imaginário contemporâneo luso sobre o continente. $O$ desgaste econômico/ideológico e o impacto na opinião pública das perdas humanas e materiais com o conflito africano deixaram alguns traumas e um certo sentimento de "paraíso branco perdido ou destruído pelos indígenas incultos e ingratos" nas imagens reproduzidas pelo retorno de milhares de colonos e mesmo por aqueles que observavam a África das terras metropolitanas (PINTO, 1999, pp. 51-64). Assim, o fim da presença colonial portuguesa não surtiu efeito significativo no campo das representações elaboradas acerca dos africanos, que continuavam marcadas pelo desprestígio.

De acordo com Isabel Castro Henriques, como efeito cumulativo de todos esses olhares, ainda hoje se encontra em grande parte dos manuais escolares utilizados em Portugal uma perspectiva de celebração dos momentos grandiosos do passado português, deslocando a Histórica da África para um papel secundário aos feitos europeus, e os africanos para uma postura passiva, perante os acontecimentos que os cercaram. 
(...) a África vai integrar a história portuguesa como elemento interno e freqüentemente secundário. Os africanos aparecem, assim, como os "descobertos", quer dizer os agentes passivos da necessidade portuguesa de descobrir. Pelo que a história da África é apenas considerada como uma fracção da história da expansão portuguesa (...) Qual o balanço da situação portuguesa pós-colonial? Não só herdou a tradição colonialista clássica, onde se verificava a existência de um racismo falsamente discreto, como foi reforçada pelo regresso a Portugal de centenas de milhar de "retornados", que injectaram na sociedade portuguesa os seus juízos de valor, a sua amargura, e por vezes, o seu rancor face às nações africanas de língua oficial portuguesa (HENRIQUES, 2004, pp. 53 e $59)$.

O desconforto com a cor negra e as características físicas dos africanos, pelo menos para um grupo significativo de pessoas, também parece não ter diminuído. Henriques destacou o estranhamento dos portugueses, em meados do século XX, com as feições faciais, a textura do cabelo ou com a própria sexualidade dos africanos, citando o curioso exemplo da campanha publicitária de um sabonete - Aregos - que teria como propriedade embranquecer a pele (HENRIQUES, 2004, p. 474).

De certa forma, mesmo transcorrido mais de meio século da confecção dessas imagens, podemos encontrar, por assim dizer, algumas janelas abertas do imaginário português que revelam os preconceitos que alguns carregam em relação às "marcas físicas" dos africanos. Um exemplo desses "deslizes" cotidianos pôde ser percebido durante a transmissão televisiva de um jogo da seleção portuguesa de futebol no qual o narrador chamava a atenção para a "carapinha nova" do jogador Nelson, nascido em Cabo-Verde e naturalizado português em 2005, ao querer referir-se ao novo penteado de cabelo do atleta em estilo trançado.

Talvez, assim como para os Antigos ou para os navegantes do início da Era Moderna, as marcas físicas que sinalizavam as fronteiras entre os africanos e os europeus, ou entre a esfera da humanidade próxima e a esfera do Outro, símbolo da negação do Eu, ainda sejam definidas pela cor da pele, pelo tipo de penteado ou pela forma como se fala ou se pronuncia um idioma. O psiquiatra afro-americano Frantz Fanon visualizava na forma infantilizada como alguns franceses se dirigiriam aos negros residentes na França, um mecanismo de interdição ou delineamento de espaços. Os africanos ou os afro-americanos seriam incapazes de falar com maestria a língua francesa, sendo essa uma das marcas de suas múltiplas incapacidades.

(...) um Branco, dirigindo-se a um negro, comporta-se exatamente como um adulto em relação a uma criança, gesticula com afetação para seduzi-lo, fala sussurrando, cheio de gentilezas, de dengos. Observamos este comportamento não apenas em um Branco, mas em centenas (FANON, 1983, p. 28). 
Para além do estranhamento com o corpo do africano, outros estereótipos sobreviveram até o final do século XX, e servem, apesar de tudo, como referência mental para os portugueses pensarem os africanos, inclusive aqueles com quem dividem as ruas, as salas de aula ou os ambientes de trabalho, em cidades como Lisboa, Setúbal ou Porto.

A insensibilidade portuguesa - como aliás européia - que não pode deixar de surpreender, deve-se a um preconceito que não está ainda morto na sociedade portuguesa contemporânea: os africanos são naturalmente escravos e estão naturalmente destinados a ser os servidores dos brancos, e dos portugueses em particular(...). A violência do preconceito, reforçado pelo inventário dos caracteres somáticos (cor da pele, tipo de cabelo, odor e maneira de falar), ainda não abandonou a sociedade portuguesa, explicando a marginalização violenta a que estão votadas as comunidades de imigrantes africanas (HENRIQUES, 2004, p. 28).

\title{
De “indígena" a imigrante: as "novas" imagens dos africanos
}

Em meados da década de 1970, um outro elemento, de extrema relevância e de certa forma incomum na história portuguesa dos últimos dois séculos, entra no cenário da construção das imagens acerca da África e dos africanos: a imigração de africanos para Portuga $^{14}$. Em um primeiro momento, que se estende até os meados dos anos 1980, ela foi decorrente tanto dos processos de independências que varreram as antigas colônias portuguesas, como dos conflitos civis que atingiram os países africanos de língua portuguesa. As dificuldades econômicas, a busca de melhores condições de vida, o "facilitador" da língua ou, ainda, a perspectiva de alguma proximidade devido às relações históricas recentes fizeram com que, imigrantes oriundos de Cabo-Verde, Angola, GuinéBissau, São Tomé e Príncipe e Moçambique passassem a desembarcar em Portugal em uma escala significativa.

\begin{abstract}
Nessa primeira vaga migratória estiveram, porém, envolvidos nacionais de todas as ex-colônias - cerca de 45.000, segundo os dados do Censo de 1981, sendo tão numerosos os angolanos então a residir em Portugal $(43 \%)$ como os caboverdianos (41\%). (...) De facto, na primeira fase da migração africana pós-1974 coexistem dois tipos: uma migração de refugiados, protagonizada por angolanos e moçambicanos, e uma migração laboral (de trabalhadores indiferenciados) construída maioritariamente por cabo-verdianos (PIRES, 1999, p. 199).
\end{abstract}

\footnotetext{
14 Excluindo o período referente ao tráfico de escravos para Portugal, e mais marcadamente as décadas iniciais do século XVI - quando a população de africanos atinge o equivalente a $10 \%$ da população lisboeta até meados do XVII - quando o uso da mão-de-obra escrava foi comum em algumas atividades econômicas --, a presença de africanos em Portugal foi sempre muito reduzida, ver Curto(1998, pp. 414-415).
} 
A partir de então podemos identificar os sinais de um novo imaginário construído sobre os africanos, ligado mais fortemente à memória da colonização, aos novos elementos do mundo contemporâneo português - como a inserção na União Européia -, e à questão do desemprego e da violência urbana. Assim, as difíceis condições de vida encontradas em Portugal pelos imigrantes, os setores da economia e das atividades laborais a eles reservados e o ressurgimento de ondas de racismo e xenofobia na Europa em relação às minorias e aos estrangeiros - oriundos da África, Ásia e América Latina principalmente que buscavam o continente nos anos 1980 e 1990, passaram a compor as principais imagens geradas sobre os africanos no imaginário português.

De acordo com os pesquisadores portugueses Manuel Gonçalves Martins (1998, p. 81) e Rui Pena Pires(1999, p. 208), em 1981, como “conseqüência [da] sub-remuneração, as condições sociais de vida dos imigrantes africanos [eram] particularmente gravosas (...) $17 \%$ residiam em barracas e 59\% em alojamentos clássicos com carências de equipamentos (...)" e de uma forma geral possuíam uma situação financeira inferior a da maioria dos portugueses. Como responsável por esse quadro, ou aliado a ele, constatou-se 10 anos depois que, $88 \%$ dos trabalhadores imigrantes empregados na construção civil eram oriundos dos PALOPs (Países Africanos de Língua Oficial Portuguesa) e que a esmagadora maioria dos imigrantes africanos desempenhava funções consideradas como não qualificadas - na construção civil, nos serviços de limpeza, na indústria e nos transportes -, sendo, portanto, mal remunerada (PIRES, 1999, pp. 205-208 e MARTINS, 1998, p. 78). Alocados em bairros periféricos, sub-empregados, alvo de ações discriminatórias pela polícia ou por parcelas da sociedade portuguesa, esses imigrantes passaram a ocupar o lugar do "africano" no imaginário português e a se confundir com as representações anteriormente elaboradas.

Se, em 1980, existiam oficialmente 58.000 estrangeiros residindo em Portugal, em 1997, esse número salta para 175.000, sendo 51\% desses composto por africanos (PIRES, 1999, pp. 201-2). A partir de meados dos anos 1980, essa imigração passa a ser fundamentalmente de ordem laboral ou associada ao reagrupamento dos familiares dos imigrantes já estabelecidos em Portugal. Porém, o perfil sócio-econômico desses imigrantes pouco foi alterado (PIRES, 1999, pp. 201-206).

Já, em $2004^{15}$, havia certa de 140 mil imigrantes de origem africana vivendo legalmente em Portugal, sem contar com a primeira ou segunda gerações de luso-africanos ou de afro-lusitanos nascidas da primeira leva de imigrantes que chegou ao país na década de 1970 e desconsiderando os imigrantes em condição ilegal. O maior contingente era

\footnotetext{
15 Os últimos dados compulsados pela pesquisa referem-se a esse ano.
} 
composto por cabo-verdianos (64.164, ou 14,3\% do total de imigrantes), seguidos por angolanos (35.264 - 7,9\%), guineenses (25.148 - 5,6\%), são-tomenses (10.483 - 2,3\%) e moçambicanos (5.010 - 1,1\%) (ACIME, 2005). Segundo as pesquisas censitárias, a maioria dos africanos residentes em Portugal ainda se enquadrava em perfis profissionais de rendimento e de qualificação que suscitavam a composição de um quadro muitas vezes dramático para sua permanência naquele país ou para obtenção. Em alguns casos perceberam-se melhores condições de vida, principalmente ao que se referem aos locais de residência (PIRES, 1999, p. 208).

De acordo com os dados do Recenseamento Geral da População de 2001, apresentadas em um relatório sobre a imigração produzido pelo Alto Comissariado para a Imigração e as Minorias Étnicas, dos 65.098 africanos economicamente ativos, 42.646, ou seja, 65,5\%, trabalhavam como "operários qualificados, semi-qualificados e não qualificados" e apenas $6.364(9,7 \%)$ apareciam como empresários ou membros dos "quadros dirigentes, intelectuais e científicos" (ACIME, 2005). Em relação ao nível de escolaridade, o mesmo censo revelou que, 12,6\% dos africanos oriundos dos PALOPs eram analfabetos, $11,2 \%$ sabiam ler e escrever, mas não tinham nenhum nível de escolaridade, 58,8\% possuíam o Ensino Básico, 13,8\% o Ensino Secundário ou Médio, e, apenas 3,7\% o Ensino Superior (idem). Outro dado relevante é o que aponta para o número de estudantes oriundos desses países africanos matriculados nas escolas portuguesas $^{16}$. Para o ano escolar de 2002-2003, eles somavam 38.605 alunos cursando os mais diversos seguimentos escolares portugueses (eram 15.247 angolanos, 13.070 caboverdianos, 5.033 guineenses, 2.143 moçambicanos e 3.112 são-tomenses). Somente no $3^{\circ}$ ciclo da Educação Básica - correspondente ao $7^{\circ}$, $8^{\circ}$ e $9^{\circ}$ anos - eram 13.784, no ano letivo 2003-4 (Gabinete de Informação e Avaliação do Sistema Educativo, 2006).

É bastante plausível que, com o convívio acentuado de um contingente tão significativo de africanos e afro-portugueses - vivendo principalmente no eixo entre Lisboa e Setúbal, como apontam os estudos sobre a imigração em Portugal -, novos estereótipos tenham aparecido, e alguns dos velhos tenham se fortalecido, como ingredientes ativos da composição do imaginário português sobre os africanos do final do século XX e início do XXI (ROCHA-TRINDADE, 2003, p. 178). De acordo com o pesquisador Manuel Gonçalves Martins, os aumentos dos fluxos migratórios para Portugal "facilitaram $e$ fortaleceram as idéias e as conviç̧ões segundo [as quais] os empregos, os costumes, e até toda a cultura dos portugueses estavam e estão em perigo", fazendo com que se criasse um quadro favorável para o

\footnotetext{
16 Sobre o desempenho escolar desses estudantes, ver o trabalho de Machado, Matias e Leal (2005).
} 
"aparecimento e fortalecimento do racismo e da xenofobia" (MARTINS, 2002, p. 82). Às posturas mentais relacionadas às intolerâncias racial e cultural associaram-se outros mecanismos de discriminação, retirados de um acervo maior de imagens elaboradas sobre os africanos.

\begin{abstract}
$\mathrm{Na}$ verdade muitos portugueses tiveram e têm preconceitos, atitudes e comportamentos discriminatórios (pensaram e pensam mal, negaram-se e negamse a dar trabalho, a arrendar casa, a deixar casar seus filhos, etc), principalmente contra alguns grupos étnicos existentes em Portugal (ciganos e pretos). Muitos portugueses consideraram (e ainda consideram) de "forma instintiva" (...) os pretos, pessoas preguiçosas e porcas (idem, pp. 82-3).
\end{abstract}

Em outra reveladora investigação, patrocinada também pelo Alto Comissariado para Imigração e Minorias Étnicas e publicada em 2006, intitulada, Imigrantes e a população portuguesa: imagens recíprocas, podemos observar a relevância adquirida por esses novos elementos na construção da imagem do africano, agora pensado como um agente de convívio cotidiano nas cidades portuguesas na figura dos imigrantes. Neste caso, alguns dados devem ser mencionados e nos auxiliam a fechar esse panorama parcial do imaginário contemporâneo elaborado sobre o africano. A pesquisa revelou que apenas $29 \%$ do total de entrevistados classificavam os africanos como "bons profissionais". No quesito competência, esse índice caiu para 26\%, e apenas 24\% diziam ser eles "sérios e honestos", contra o percentual de $40 \%, 43 \%$ e $40 \%$ quando a pergunta era sobre a imagem do português construída pelos próprios portugueses (Lages, 2006, p. 250).

Já acerca dos possíveis “desvios sociais" praticados por um determinado grupo para nos prendermos a terminologia empregada pela pesquisa - os africanos foram associados à violência e ao tráfico de entorpecentes nas principais cidades portuguesas. Neste caso, 64,8\% dos entrevistados relacionou-os à violência e 54,8\% ao tráfico de drogas (Lages, 2006, p. 250).

Condensado em dados estatísticos ou não, o imaginário português acerca do continente e de suas populações está carregado por dois grandes conjuntos de imagens. $\mathrm{O}$ primeiro ainda refere-se à experiência colonial, no qual se prioriza a perspectiva da história dos portugueses em África, seja na fase mítica dos "Descobrimentos" dos séculos XV e XVI, seja na fase, digamos, empírica, da montagem do "Império Colonial" dos séculos XIX e XX. Nestes últimos dois séculos, o português aparece como único agente efetivo da história e cabe a ele a ação civilizadora e modernizadora sobre os africanos (escravos, indígenas, colonizados, atrasados e primitivos).

Já como resultado dos contatos das últimas décadas, marcadas pelo aumento da imigração africana para a Europa, ocorreu uma (re)apropriação significativa de imagens 
circulantes outrora e a formulação de um novo conjunto de estereótipos, sintetizadas pelos seguintes estigmas: seres incompetentes e pouco confiáveis; "preguiçosos por natureza"; mão-de-obra desqualificada e mal remunerada; baixo nível social e educacional; estando associados também às condições de moradia precárias; à violência urbana; ao uso e tráfico de drogas.

Já de acordo com a pesquisadora Neusa Maria de Gusmão, que desenvolveu interessante trabalho acerca dos jovens e crianças africanas nas escolas portuguesas, construiu-se naquele país, ao longo das últimas décadas, uma nova categoria para definir o significado de "africano". Resultante de um conjunto de idéias oriundas do imaginário do próprio período colonial, da traumática guerra em África e dos olhares daqueles que, sendo integrantes da União Européia, se vêem em condição privilegiada, ao mesmo tempo em que se sentem invadidos pelas levas de imigrantes africanos, essa "nova" categoria de africano se desdobra em dois sentidos, digamos assim, não tão novos. Nesse caso, para o português contemporâneo, o africano "se torna sinônimo de negro", e o negro se confunde com o africano. Por outro lado, ser africano em Portugal significa também ser imigrante, estrangeiro e pobre. "As categorias se cruzam e o quotidiano se conflita" (Gusmão, 2004, p. 111). Mesmo que a noção de "imigrante, estrangeiro e pobre" seja também atribuída a indivíduos de outras nacionalidades, que compõem hoje grandes contingentes naquele país, como os brasileiros e os ucranianos, aos africanos ainda compete uma classificação diferenciada.

\footnotetext{
Africano é então todo e qualquer cidadão de origem africana, seja ou não nascido em Portugal, tenha ou não nacionalidade portuguesa, seja ele "preto" ou "mestiço", independe da situação legal que possua (...) Africano é uma categoria operacional, mais do que de origem, esta sim diversa e múltipla. Por outro lado, africano é, antes de mais nada, categoria referencial que opera o senso comum no quotidiano das vivências entre os imigrantes negros e portugueses de modo a definir qualquer pessoa de pele negra e, com isso, atribuir-lhe a condição "estrangeira” (Gusmão, 2004, p. 111).
}

Se o africano próximo é caracterizado por essas representações, as imagens sobre os africanos na África e sobre o próprio continente são definidas a partir de uma série de marcos característicos. Por um lado é um mundo marcado por guerras, massacres, violência, corrupção, desorganização e atraso econômico, apesar dos esforços de cooperação européia, inclusive portuguesa, apontando para a falência gerencial e suposta incapacidade africana de auto-gestão. Por outro, o continente é definido como o espaço da fome, doenças e tragédias, símbolos de uma terra esquecida e mergulhada no caos; e, a essas imagens juntam-se aquelas de uma África Portuguesa perdida em um tempo quase 
mítico, seja o das Grandes Navegações, seja o período colonial, do qual muitos nutrem um sentimento de nostalgia e saudades.

\section{Os reflexos da África no espelho imaginário português}

Ao pensarmos o imaginário coletivo como um reflexo das relações cotidianas que transcorrem em uma sociedade, e as representações como as traduções ou reinvenções dos "objetos" observados, fica claro que, circulam em Portugal um número expressivo de imagens e de discursos que lançam os africanos e a África - no passado e no presente para posições de pouca importância na trajetória histórica da humanidade, mantendo ainda, muitas vezes, expressões negativas ou pejorativas. Compete sempre lembrar também e, isso parece evidente, que num caminho paralelo a esse, outras idéias sobre a questão foram elaboradas e receberam sentidos distintos.

Dessa forma, seja nas "selvas" do imaginário colonial dos séculos XIX e XX, seja nas cidades portuguesas do século XXI, o lugar ocupado pelos africanos no imaginário coletivo português - com as evidentes exceções - está marcado pelo binômio composto pelos estigmas de sua suposta inferioridade e pelos olhares "lusocêntricos".

\section{Referências Bibliográficas}

1. ACIME (ALTO COMISSARIADO PARA A IMIGRAÇÃO E AS MINORIAS ÉTNICAS). Estatísticas da Imigração. Lisboa: ACIME, 2005.

2. ALEXANDRE, Valentim. A África no Imaginário Político Português (séculos XIX-XX). In: Actas do Colóquio Construção e Ensino da História da Africa. Lisboa: Linopazas, 1995, pp. 231-244.

3. ALEXANDRE, Valentim. O Império Africano (séculos XIX e XX): as linhas gerais. In . O Império Africano, séculos XIX e XX. Lisboa: Colibri, 2000, pp. $11-28$.

4. BORGES, João. A constituição do Estado Moderno em África: o problema das fronteiras. Brief Papers, no 2, Lisboa, CEsA, 1995.

5. CURTO, Diogo Ramada. A língua e o Império. In ALEGRIA, Maria Fernanda, et al (orgs.). História da Expansão Portuguesa: a formação do Império, vol. 1. Lisboa: Círculo de Leitores, 1998, pp. 414-433.

6. DÖPCKE, Wolfgang. A vinda longa das linhas retas: cinco mitos sobre as fronteiras na África Negra. In Revista Brasileira de Política Internacional, 42 (1), pp. 77109, 1999.

7. FANON, Frantz. Pele Negra, Máscaras Brancas. Rio de Janeiro: Fator, 1983.

8. GUSMÃO, Neusa Maria Mendes de. Os filhos da África em Portugal: Antropologia, multiculturalidade e educação. Lisboa: Imprensa de Ciências Sociais, 2004. 
9. HENRIQUES, Isabel Castro Os pilares da diferença: relações Portugal-África, séculos XV-XIX. Lisboa: Caleidoscópio, 2004.

10. HERNANDEZ, Leila Leite. A África na sala de aula: visita à história contemporânea. São Paulo: Selo Negro, 2005.

11. LAGES, Mário F., et al. Os imigrantes e a população portuguesa imagens recíprocas. Lisboa: Alto Comissariado para Imigração e Minorias Étnicas (ACIME), 2006.

12. LÉONARD, Yves. O Império Colonial Salazarista. In BETHENCOURT, Francisco e CHAUDHURI, Kirti (orgs.). História da Expansão Portuguesa, vol. V. Lisboa: Círculo de Leitores, 1999, pp. 10-30.

13. LÉONARD, Yves. O Ultramar Português. In BETHENCOURT, Francisco e CHAUDHURI, Kirti (orgs.). História da Expansão Portuguesa, vol. V. Lisboa: Círculo de Leitores, 1999 a, pp. 31-50.

14. MACHADO, Fernando Luís, MATIAS, Ana Raquel e LEAL, Sofia. Desigualdades sociais e diferenças culturais: os resultados escolares dos filhos de imigrantes africanos. In Análise Social, vol. XI (176), 2005, pp. 695-714.

15. MARTINS, Manuel Gonçalves. Imigrações, racismo e xenofobia em Portugal (1974-2002). In Africana, no 25, 2002, pp. 71-90.

16. MARTINS, Manuel Gonçalves. Migrações internacionais e aumento do racismo e da xenofobia na União Européia. In Africana, n 16, março, 1998, pp. 75-90.

17. MARTINS, Oliveira. O Brasil e as Colónias Portuguesas. Lisboa: Guimarães, 1978.

18. OLIVA, Anderson Ribeiro. Lições sobre a África: diálogos entre as representações dos africanos no imaginário Ocidental e o ensino da História da África no Mundo Atlântico (1990-2005). Brasília: UnB, Tese de Doutorado, 2007.

19. PAULO, João Carlos. Da educação colonial portuguesa a ensino no Ultramar. In BETHENCOURT, Francisco e CHAUDHURI, Kirti (orgs.). História da Expansão Portuguesa: Último Império e recentramento (1930-1998), vol. 5. Lisboa: Temas e Debates, 2000, pp. 304-333.

20. PINTO, António Costa. Portugal e a resistência à Descolonização. In BETHENCOURT, Francisco e CHAUDHURI, Kirti (orgs.). História da Expansão Portuguesa, vol. V. Lisboa: Círculo de Leitores, 1999, pp. 51-64.

21. PIRES, Rui Pena. A Imigração. In BETHENCOURT, Francisco e CHAUDHURI, Kirti (org.). História da Expansão Portuguesa: Último Império e Recentramento, vol. 5. Lisboa: Círculo de Leitores, 1999, pp. 197-211.

22. ROCHA-TRINDADE, Maria Trindade. A realidade da imigração em Portugal. In Actas do I Congresso sobre Imigração. Lisboa: ACIME, 2003, pp. 171-198.

23. UZOIGWE, Godfrey N. Partilha européia e conquista da África: apanhado geral. In BOAHEN, A. Adu. (org). História Geral da Africa VII: A África sob dominação colonial, 1880-1935. São Paulo: Ática; Unesco, 1991, pp. $43-67$.

24. VALVERDE, Paulo. O Corpo e a busca de lugares da perfeição: escritas missionárias da África Colonial Portuguesa, 1930-60. In Etnográfica, Vol. I (1), 1997, pp. 73-96.

25. ZAMPARONI, Valdemir. Entre Narros e Mulungos: Colonialismo e paisagem em Lourenço Marques (1890-1930). São Paulo: Universidade de São Paulo, Tese de Doutorado, 1998. 
26. ZAMPARONI, Valdemir. De escravo a cozinheiro: colonialismo e racismo em Moçambique. Salvador: Edufba, 2007. 